\title{
Injúria renal aguda em paciente com síndrome nefrótica: Relato de Caso
}

\author{
Acute renal injury in a patient with nephrotic syndrome: Case Report
}

Stephannie Santos Rangel ${ }^{* *}$, Alexandre Mitsuo Mituiassu*

Como citar esse artigo. Rangel,

S.S.; Mituiassu, A.M.. Injúria renal aguda em paciente com síndrome nefrótica: Relato de Caso. Revista de Saúde. 2018 Jul./Dez.; 09 (2): 44-48

\section{Resumo}

A Síndrome Nefrótica é uma doença do tipo glomerular com etiologias variadas. Apresenta-se com proteinúria, hipoalbuminemia, edema e hipercolesterolemia. A fisiopatologia dessa síndrome ocorre pelo aumento da filtração glomerular de macromoléculas devido a uma alteração na barreira de filtração da parede capilar, podendo ser seletiva ou não seletiva. A doença de lesões mínimas (DLM) é uma etiologia primária dessa síndrome, se apresenta principalmente na infância, mas pode ser encontrada em todas as faixas etárias. Em alguns casos a DLM pode se associar a injúria renal aguda (IRA), um evento incomum, porém de extrema importância. Quando presente pode estar associado a níveis graves de proteinúria e hipoalbuminemia. Este trabalho relata um caso de síndrome nefrótica que evoluiu com IRA, cujo objetivo foi analisar a evolução clínica e discutir o manejo terapêutico deste agravo com embasamento em referências bibliográficas atualizadas.

Palavras-chave: Síndrome Nefrótica, Injúria Renal Aguda, Necrose Tubular Aguda.

\begin{abstract}
Nephrotic syndrome is a glomerular disease type with a variety of etiologies. It presents with proteinuria, hypoalbuminemia, edema and hypercholesterolemia. The pathophysiology of this syndrome occurs by the increase of glomerular filtration of mac-romolecules due to an alteration in filtration barrier of capillary wall and can be selective or non selective. The disease of minimal lesions (DML) is a primary etiology of this syn-drome, it presents mainly in childhood, but can be find in all age groups. In some cases, DML may be associated with a renal failure acute (RFA), an uncommon event, but con-sidered extremely important. When it is present can be associated with serious levels of proteinuria and hypoalbuminemia. This analysis describes a case of nephrotic syndrome that evolved with RFA, whose objective was to measure the clinical evolution and dis-cuss the therapy manipulation with base in updated bibliographic references.

Keywords: Nephrotic Syndrome, Acute Renal Injury, Acute Tubal Necrosis .
\end{abstract}

\section{Introdução}

A Síndrome Nefrótica pertence ao grupo de doenças glomerulares e se ca racteriza pela presença de proteinúria, hipoalbuminemia, edema, hipercolesterolemia e lipidúria. Pode apresentar função renal preservada ou ser associada à disfunção renal progressiva. As etiologias primárias pertencentes a essa síndrome são a doença de lesões mínimas (DLM), glomeruloesclerose segmentar e focal (GESF), nefropatia membranosa (NM) e glomerulonefrite membranoproliferativa (GNMP). Sua forma varia muito com a idade, logo a DLM predomina principalmente na infância, mas pode ser encontrada em todas as faixas etárias. Já a GESF é mais comum em adultos ${ }^{1}$.

A fisiopatologia dessa síndrome ocorre pelo aumento da filtração glomerular de macromoléculas devido a uma alteração na barreira de seletividade da parede capilar, permitindo a passagem de moléculas com carga negativa como a albumina. Assim, a albumina sérica baixa resulta em edema pela perda de líquido para o espaço extra vascular. Também são encontrados lesões na barreira de filtração do tipo não seletiva, permi-tindo a passagem de macromoléculas do plasma, tanto albumina quanto outras proteínas de diferentes tamanhos. Já o mecanismo que leva a hipercolesterolemia e a lipidúria é resultado compensatório do fígado ao aumento da produção de proteínas ${ }^{1,2}$.

O desenvolvimento de injuria renal aguda (IRA)

Afiliação dos autores: † Discente do Curso de Graduação em Medicina da Universidade de Vassouras, Vassouras, Rio de Janeiro, Brasil. vinycius.andre@gmail.com

\$ Docente do Curso de Graduação em Medicina da Universidade de Vassouras, Vassouras, Rio de Janeiro, Brasil.

* Email de correpondência: ss_rangel@hotmail.com 
associada é um evento incomum, mas quando ocorre normalmente está relacionado com proteinúria grave e níveis baixos de albumina sérica. Podemos considerar mecanismos variados, tais como depleção de volume evoluindo com injuria pré renal ou necrose tubular aguda, edema intra-renal (nefrosarca), trombose de veia renal, mudança de doença de base e nefrotoxicidade por drogas ${ }^{1,2,3}$

Na DLM a única anormalidade estrutural é a fusão e retração dos processos podocitários. A maioria dos casos é idiopática, mas também podem estar associados a neoplasias ou a medicamentos. Sua apresentação clínica é semelhante às outras causas de síndrome nefrótica ${ }^{1}$. Embora apresente com maior frequência em crianças (2 a 7 em cada 100.000), também é uma importante causa de síndrome nefrótica em adultos. Sua incidência varia geograficamente, cerca de 1 por milhão de população, nos quais há um diagnóstico diferencial grande e a resposta ao tratamento com os corticoides é menos provável. A biópsia renal entra como um fator determinante para elucidar o diagnóstico e guiar o seu tratamento ${ }^{1}$.

O presente trabalho relata um caso incomum de síndrome nefrótica que evoluiu para injúria renal aguda em paciente adulto sem comorbidades, que obteve no final do tratamento reversão da lesão renal. Seu objetivo foi analisar a evolução clínica, a necessidade de biópsia para elucidação do caso, o manejo do tratamento e os diagnósticos diferenciais, baseado em referências bibliográficas atualizadas.

\section{Relato de caso}

Paciente do sexo masculino, 28 anos, natural e residente do Município de Vassouras- RJ foi admitido na enfermaria de Nefrologia do Hospital Universitário de Vassouras (HUV) pelo departamento de emergência, com quadro de dispneia progressiva aos esforços e edema importante em membros inferiores.

Paciente relatou que a três semanas da internação fez uso de creatina e suplemento proteico. A partir desse momento iniciou um quadro de edema progressivo. Procurou um nefrologista que suspeitou de síndrome nefrótica e o orientou a procurar o serviço do HUV.

No dia da internação, o paciente apresentava dispneia aos pequenos esforços. Pressão arterial sistêmica 120 x $90 \mathrm{mmHg}$. Ao exame do aparelho respiratório o murmúrio vesicular estava abolido em bases de ambos hemitórax. O abdome estava distendido do tipo ascítico. Os membros inferiores apresentavam quadro edemigênico em grau avançado com presença do sinal de cacifo (figura 1). Peso do paciente de 101 $\mathrm{kg}$.

$\mathrm{Na}$ admissão foram solicitados a radiografia de tórax, que evidenciou derrame pleural bilateral, e

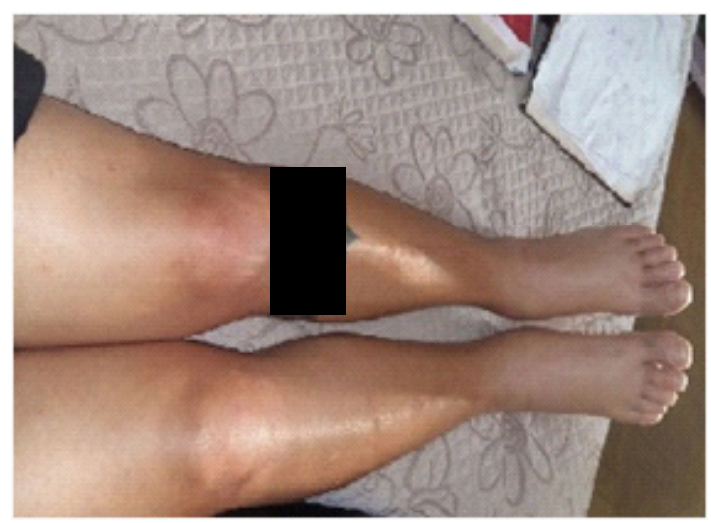

Figura 1. Paciente em anasarca antes do inicio do tratamento.

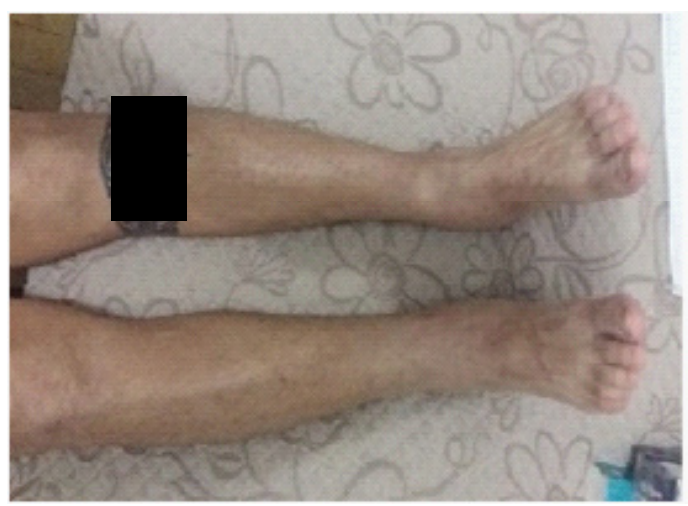

Figura 2. Paciente após dez dias de tra-tamento.

exames laboratoriais: hematócrito: $52 \%$, hemoglobina: $17,5 \mathrm{~g} / \mathrm{dL}$, Leucócitos: $11.040 / \mathrm{mm}^{3}$, com diferencial 0/2/0/0/0/63/30/05, plaquetas: 296 mil, sódio: 130 $\mathrm{mEq} / \mathrm{L}$, potássio: $5,0 \mathrm{mEq} / \mathrm{L}$ uréia: $100 \mathrm{mg} / \mathrm{dL}$, creatinina: $1,5 \mathrm{mg} / \mathrm{dL}$, proteínas to-tais: 4,2 , albumina: 1,60 g/dL, globulina: $2,60 \mathrm{~g} / \mathrm{dL}$, TGO: $56 \mathrm{U} / \mathrm{L}$, TGP: 40 U/L, cálcio: $1,08 \mathrm{nmol} / \mathrm{L}$, lactato: $11 \mathrm{mg} / \mathrm{dL}(4,5-19,8)$. As sorologias para hepatite B, C, HIV e VDRL foram negativos, exames trazidos pelo paciente. No exame de urina apresentou +++ de proteína, 7 hemácias , alguns cilindros granulosos e alguns cilindros hialinos.

Foi instituída terapia com restrição hídrica, furosemida intravenosa $20 \mathrm{mg}$ de $6 / 6 \mathrm{~h}$, heparina profilática 5000 UI subcutânea. No segundo dia de internação hospitalar, como não houve resposta clínica, foi iniciado tratamento com corticoide por pulsoterapia de três dias com metilprednisolona $1 \mathrm{~g} /$ dia seguido de prednisona $80 \mathrm{mg} /$ dia via oral, profilaxia para estrongiloidíase com ivermectina e programado biópsia renal.

Os marcadores FAN, ANCA, anti-DNA foram negativos. A relação proteí-na/creatinina na urina era de 4,68, dentro da faixa nefrótica. A eletroforese de 
Tabela 1. Exames Laboratoriais realizados durante a internação

\begin{tabular}{|c|c|c|c|c|c|c|c|c|c|c|c|}
\hline \multicolumn{12}{|l|}{ Exames } \\
\hline & $1^{\circ}$ & $2^{\circ}$ & $3^{\circ}$ & $4^{\circ}$ & $5^{\circ}$ & $6^{\circ}$ & $7^{\circ}$ & $8^{\circ}$ & $9^{\circ}$ & $10^{\circ}$ & $11^{\circ}$ \\
\hline Hematócrito & 52 & 45 & 42 & 37 & 41 & 39 & & 41 & 38 & & \\
\hline Hemácias & 5.93 & 5.23 & 4,84 & 4,52 & 4,65 & 4,41 & & 4,58 & 4,36 & & \\
\hline Hemoglobina & 17,5 & 15,9 & 14,9 & 13,1 & 14,3 & 13,6 & & 14,1 & 13,4 & & \\
\hline Leucócitos (mil) & 11 & 18 & 22 & 17 & 16 & 23 & & 10 & 30 & 12 & 13 \\
\hline \multicolumn{12}{|l|}{ Basófilos } \\
\hline Eosinófilos & 2 & & & & & & & & & & 2 \\
\hline \multicolumn{12}{|l|}{ Mielócitos } \\
\hline \multicolumn{12}{|l|}{ Metamielócitos } \\
\hline Bastões & 0 & 3 & 2 & 1 & 1 & 1 & & 3 & 28 & 2 & 1 \\
\hline Segmentados & 63 & 88 & 89 & 90 & 93 & 90 & & 84 & 70 & 86 & 78 \\
\hline Linfócitos & 30 & 6 & 6 & 7 & 4 & 7 & & 8 & 1 & 8 & 1 \\
\hline Monócitos & 5 & 3 & 3 & 2 & 2 & 2 & & 5 & 1 & 4 & 2 \\
\hline Plaquetas (Mil) & 296 & 246 & 231 & 207 & 189 & 189 & & 180 & 149 & 99 & 119 \\
\hline Lactato & 11 & & & & & & & & & & \\
\hline TAP & & 14,1 & & & & & 13 & & & & \\
\hline PTT & & 24 & & & & & 28 & & & & \\
\hline INR & & 1.8 & & & & & 1 & & & & \\
\hline Sódio & 130 & 130 & 131 & 133 & 138 & 138 & & 140 & 137 & 140 & 138 \\
\hline Potássio & 5 & 6,5 & 5,4 & 4,9 & 3,6 & 3,6 & & 3,6 & 3,1 & 3,8 & 3,6 \\
\hline PCR & & & & & & & & & & 109 & 68 \\
\hline Uréia & 100 & 143 & 174 & 184 & 209 & 176 & & 178 & 186 & 141 & 119 \\
\hline Creatinina & 1,5 & 2,6 & 3,4 & 2,5 & 2,5 & 2,1 & & 1,5 & 2,2 & 1,2 & 1,4 \\
\hline Proteinas Totais & 4,2 & 4,2 & 3,9 & 3,9 & 4,4 & 4,2 & & 4,4 & 3,8 & 4 & 4,2 \\
\hline Albumina & 1,6 & 1,4 & 1,7 & 1,6 & 1,8 & 1,6 & & 1,5 & 1,3 & 1,2 & 1,4 \\
\hline Globulina & 2,6 & 2,8 & 2,2 & 2,3 & 2,6 & 2,6 & & 2,9 & 2,5 & & \\
\hline TGO & 56 & 54 & & & & 40 & & & & & \\
\hline TGP & 40 & 45 & & & & 32 & & & & & \\
\hline Colesterol total & & 787 & & 638 & & 582 & & 649 & 560 & & \\
\hline CK Total & & 324 & & & & & & & & & \\
\hline Acido Urico & & 9,3 & & & 11,3 & & & & & & \\
\hline Cálcio & 1,08 & 0 & & & 0,17 & & 1,04 & 0,98 & & & \\
\hline
\end{tabular}

proteínas no sangue evidenciou os seguintes resultados: albumina: 46,1\% (55,1 a 65,7\%), $\alpha 19,0 \%$ (3,1 a 5,6\%), $\alpha 219,8 \%(8,0$ a $12,7 \%), \beta 18,0 \%$ (4,9 a 7,2 \%), $\beta 2$ $8,0(3,1$ a $6,1 \%) \quad \gamma 9,1 \%(10,3$ a $18,2 \%)$, relação $\mathrm{A} / \mathrm{G}$ 0,86 , proteínas totais: $4,10 \mathrm{~g} / \mathrm{dL}$, proteína monoclonal: ausente, foi possível observar uma proteinúria do tipo seletiva. Os complementos séricos C3: $168 \mathrm{mg} / \mathrm{dL}$ e C4: $43 \mathrm{mg} / \mathrm{dL}$ estavam dentro dos limites de normalidades.
No terceiro dia de internação, optou-se por início de terapia renal substitutiva (hemodiálise) devido à injúria renal aguda e hipervolemia refratária a tratamento clínico (Tabela 1). Durante o tratamento evoluiu com melhora progressiva, apresentando no $10^{\circ} \mathrm{DIH}$ perda de $7 \mathrm{~kg}$ no período e aumento da diurese de $660 \mathrm{~mL}$ em 24 horas para $1850 \mathrm{~mL}$ em 24 horas.

Já no $12^{\circ} \mathrm{DIH}$ apresentou febre de $38,2^{\circ} \mathrm{C}$ devido a uma infecção sistêmica em que o sitio primário era 
a colonização do cateter femoral de diálise. A conduta inicial foi a retirada imediata deste, antibioticoterapia com vancomicina associada à ciprofloxacino e a coleta de hemocultura. Nesse momento, o paciente iniciou um quadro de poliúria com uma diurese de $4.120 \mathrm{~mL}$ em 24 horas. Foi então realizada no $13^{\circ} \mathrm{DIH}$ a biópsia renal, guiada pela tomografia computadorizada, que transcorreu sem intercorrências.

Após cinco dias da coleta, a hemocultura evidenciou crescimento de Staphylococcus aureus sensível à vancomicina, permanecendo este antibiótico e retirado a ciprofloxacino.

No $18^{\circ} \mathrm{DIH}$, já com melhora do quadro de dispneia e da síndrome edemigênica (Figura 2), apresentou recuperação da função renal e da infecção. Foi então pro-gramado a alta hospitalar com uso da prednisona 80 $\mathrm{mg} /$ dia e acompanhamento ambulatorial.

O resultado do anatomopatológico demonstrou ausência de alterações histológicas glomerulares significativas. Foram evidenciadas alterações degenerativo-necróticas tubulares (Necrose Tubular Aguda), nefrocalcinose, compartimentos interstíciovascular com estrutura conservada, imunofluorescência com padrão não imune. $\mathrm{O}$ conjunto anatomo-clínico foi consistente com síndrome nefrótica primária com complexo de lesões mínimas/ glomeruloesclerose segmentar e focal não amostrada. A imunofluorescência renal evidenciou ausência de depósitos fluorescentes glomerulares significativos e padrão de glomerulopatia não imune.

Durante o acompanhamento ambulatorial, realizou uso de prednisona $1 \mathrm{mg} / \mathrm{kg} /$ dia por 16 semanas, obtendo remissão completa do quadro. Foi realizada a retirada progressiva do uso de corticoide e após seis meses não apresentou sinais de recidiva da doença.

\section{Discussão}

A glomerulopatia de alterações mínimas do adulto com injúria renal aguda está fortemente relacionada com a idade avançada, arteriosclerose, níveis elevados de pressão arterial sistólica e do aumento da proteinúria com a hipoalbuminemia ${ }^{4,5}$. Apesar das principais características, o paciente é um adulto jovem, sem comorbidades, não seguindo o padrão da literatura, contudo o caso apresenta semelhança com os demais aspectos.

O fenômeno de injuria renal aguda na DLM foi descrito pela primeira vez por Chamberlain et al. em $1966^{2}$, sendo relatado posteriormente por outros autores ${ }^{5,7}$. Apesar disso, ainda continua sendo um caso incomum se comparado com o relatado na literatura, que é a presença da taxa de filtração glomerular preservada ${ }^{5}$. No caso descrito foi realizada a biópsia, já que é fundamental na síndrome nefrótica e importante para definir os diagnósticos diferenciais levantados sobre a lesão renal.

Do ponto de vista histológico, a DLM se caracteriza pela pobreza ou até mesmo pela ausência de achados na microscopia óptica, porém na microscopia eletrônica é caracterizado a alteração de fusão dos processos podocitários ${ }^{2,4,5}$. Por isso, foi definido no caso descrito a DLM, por excluir alterações significativas na biópsia compatíveis com outras etiologias de doenças glomerulares.

A necrose tubular aguda foi identificada na microscopia, fato compatível com a literatura, pois $71 \%$ desses casos possuem esse achado ${ }^{4}$. Algumas teorias são propostas para definir o porquê de alguns pacientes desenvolverem a necrose dos túbulos renais. A principal delas se baseia na relação da diminuição da pressão oncótica plasmática, levando a uma queda do volume efetivo da circulação, provocando a isquemia renal. Fato que pode ser observado no caso relatado, já que os níveis de albumina do paciente se apresentam em níveis graves e elevada perda de volume para o interstício ocasionando a injúria aguda do tipo pré renal.

Outros mecanismos são descritos como causa de IRA no paciente com síndrome nefrótica. Pode ocorrer o desenvolvimento de edema intersticial, uma glomerulonefrite crescêntica sobreposta, trombose de veia renal bilateral, aumento do risco de piora de função renal relacionado a anti-inflamatórios não esteroidais e inibidores de enzima de conversão, e maior risco de nefrite intersticial alérgica secundário a drogas, inclusive diuréticos ${ }^{1}$.

A sepse também deve ser considerada como um diagnóstico diferencial pelo risco elevado na síndrome nefrótica. Grandes coleções líquidas formam um meio para a proliferação de microrganismos e com o edema os fatores imunes ficam diluídos, prejudicando a habilidade de eliminar essas bactérias. Quando a infecção evolui para a sepse pode ocorrer IRA, pelo aumento da depleção de volume resultando em IRA pré renal ${ }^{1}$ ou devido lesão renal intrínseca relacionada à sepse. A infecção no sítio do cateter de acesso profundo do caso não levantou suspeitas para a causa da IRA do paciente já que a infecção foi posterior ao inicio da hemodiálise, em que o paciente já estava com lesão renal.

A lesão renal é na maioria dos casos resolvida quando os pacientes entram no processo de remissão ${ }^{3}$. Importante relatar que o paciente apresentou níveis graves de proteinúria e hipoalbuminemia, necessitando de terapia renal substitutiva e ao final da internação tinha a quase completa recuperação da função renal.

De acordo com a diretriz atual de tratamento, o Kidney Disease: Improving Global Outcomes (KDIGO) recomenda a corticoterapia imediata aos pacientes com prednisona ou prednisolona, uma dose alta administrando dose única diária de $1 \mathrm{mg} / \mathrm{kg}$ e posteriormente mantido por no mínimo 4 semanas se ocorrer remissão completa, 
e no máximo 16 semanas na ausência de remissão ${ }^{6}$.

A ciclofosfamida ou os inibidores de calcineurina (ciclosporina, tacrolimus) entram como opções em pacientes com contraindicações, intolerância a altas doses de cor-ticoide ou com recaídas frequentes. Esta ocorre com uma taxa de $40 \%$, encontrada principalmente em adultos que tiveram DLM quando criança ou com etiologia secundária como doença de Hodgkin, terapia com lítio ou o uso de anti-inflamatórios não esteroides. A DLM é extremamente sensível a corticoterapia em crianças, no entanto os adultos podem responder mais lentamente em até 4 meses de tratamento. A escassez de trabalhos que relatem o acompanhamento do tratamento em adultos prejudica ainda mais a equipe a nortear um caminho para a recuperação desses pacientes ${ }^{6}$.

No caso foi adotado a terapia com restrição hídrica, uso de diurético de alça para diminuir o quadro edemigênico e antes de iniciar terapia via oral com prednisona, optou-se por fazer pulsoterapia com metilprednisolona por três dias devido à gravidade do pa-ciente e a intolerância da via oral. O nível importante de edema possivelmente prejudicaria a absorção pelas alças também comprometidas.

\section{Referências}

1. Johnson RJ, Feehally J, Floege J. Nefrologia Clínica: Abordagem Abrangente. Rio de Janeiro: Elsevier, 2016, 3660p.

2. Smith JD, Hayslett JP. Reversible Renal Failure in the Nephrotic Syndrome. Am J Kidney Dis. 1992; 19: 201-213.

3. Stellato $T$ et al. Severe Reversible Acute Renal Failure in Idiopathic Nephrotic Syndrome. JNephrol. 2010; 717-724.

4. Jennette JC. Falk RJ. Adult minimal change glomerulopathy with acute renal failure. Am J Kidney Dis. 1990; 16: 432- 437.

5. Abraham T. Nayak-Rao S. Shenoy P. Revisiting Acute Kidney Injury in Minimal Change Disease a Case Report and of Literature. ARC Journal of Nephrology. 2010; 2(1): 1-5.

6. Kidney Disease: Improving Global Outcomes (KDIGO) CKD Work Group. KDIGO. Clinical Practice Guideline for Glomerulonephritis. 2012; 2(5): $177-180$ 